\title{
Management of hypertension in Nigeria: The barriers and challenges
}

\author{
Nelson I Oguanobi*
}

Department of Medicine, University of Nigeria Teaching Hospital, Enugu, Nigeria

\begin{abstract}
In recent years there has been increasing concern about the growing burden of cardiovascular disease (CVD) in developing countries. Systemic hypertension remains the commonest form of CVD and is identified as a key modifiable risk factor for cardiovascular morbidity and mortality. Primary and secondary prevention of cardiovascular adverse events are public health priorities. This review highlights the potential barriers and challenges to hypertension care in Africa's most populous country, Nigeria, and proffers relevant recommendations.
\end{abstract}

\begin{abstract}
More Information
*Address for Correspondence: Dr. Nelson I Oguanobi, Department of Medicine University of Nigeria, Teaching Hospital, Enugu, Nigeria, Email: nelson.oguanobi@unn.edu.ng; nelifyik@yahoo.com
\end{abstract}

Submitted: January 11, 2021

Approved: March 18, 2021

Published: March 19, 2021

How to cite this article: Oguanobi NI. Management of hypertension in Nigeria: The barriers and challenges. J Cardiol Cardiovasc Med. 2021; 6: 023-025.

DOI: 10.29328/journal.jccm.1001112

Copyright: (c) 2021 Oguanobi NI. This is an open access article distributed under the Creative Commons Attribution License, which permits unrestricted use, distribution, and reproduction in any medium, provided the original work is properly cited.

(W) Check for updates

OPEN ACCESS
Cardiovascular disease (CVD) is responsible for a large proportion of death and disability worldwide, contributing $43 \%$ to the global mortality figure and $15 \%$ to the total global burden of diseases in terms of disability-adjusted life years (DALYs) [1-3]. Systemic hypertension remains the commonest form of CVD accounting for over $80 \%$ of the global disease burden $[2,4]$. In Nigeria, hypertension is the commonest form of cardiovascular disorder, occurring in $86.4 \%$ of patients with cardiovascular disorders and in $38 \%$ of the adult population [5-7].

The pathogenesis of essential hypertension is multifactorial [8]. Numerous physiological alterations have been described in hypertensive individuals, including abnormalities of renal sodium handling, neurohormonal and adrenergic overactivity, endothelial dysfunction, vascular smooth muscle hypertrophy, systemic inflammation, reduced fibrinolytic potential, and enhanced oxidative stress [8-10].

\section{Barriers and challenges to hypertension care}

Hypertensive heart disease, defined by the presence of left ventricular hypertrophy in the absence of any cause other than arterial hypertension, has been long considered as one of the most common aetiological conditions predisposing to heart failure [11,12]. There are several barriers to hypertension control at individual, institutional, societal and health care provider levels in Nigeria. These barriers are largely responsible for the observed increase in the incidence of complications in hypertensive patients in spite of the continuous progress of antihypertensive strategies over the years [2,13-15]. Improvement in patient outcome has not kept pace with increase in knowledge about the aetiopathophysiology of the disease [13-15]. The wide 'gap' between guidelines and practice is contributory [16,17]. Evidence from research surveys reveals a lack of awareness of these guidelines among primary care physicians [17].

In many countries, primary health care facilities play vital role in the detection, risk factor assessment and management of hypertension $[14,18,19]$. However, in Nigeria the detection and management of hypertension in the primary health care setting is poor [18]. There is a shortage of well trained and qualified health care personnel as well as inadequate medical facilities in these primary care centres. Even at the secondary and tertiary health care facilities, there are inadequate numbers of trained professionals. The implication on the health system is quite enormous for two reasons. Firstly, the consequence of the medical workforce shortage is a high patient to doctor ratio in the health care system. Nigeria, with the year 2021 projected population of about 211,400,708 people has approximately 35,000 doctors currently practicing in its health care system $[20,21]$. This gives a crude estimate of doctor to population ratio of 1 per 6,040, a figure that is much lower than the World Health Organization recommended benchmark of 1 per 1000 and a further depreciation from a 2014 survey report of doctor to population ratio of 1.95 per 1000 population [22,23]. This disproportionate doctor- 
population ratio puts increased workload on the relatively few available doctors. This situation has continued to deteriorate with increasing migration of doctors from Nigeria to "greener pastures" abroad. Current statistics show that 1 in 4 doctors trained in this country are currently working in developed countries [24,25]. The critical shortages in human resources for medical practitioners and the mal-distribution of the available medical workforce constitute one of the key causes of exclusion to access to quality health care, and this is especially true in rural communities.

Another dimension to the depletion in medical health care workforce is the unpleasant reduction in patient/doctor interaction time due to excess work pressure and unfriendly consulting clinics environment. Adequate interaction between doctors and patients has implications for individual and public health and has the potential to improve many facets of the health care delivery system from quality to outcomes.

Limited knowledge of hypertension by healthcare professionals, among other factors, has been identified as being responsible for poor hypertension control. Ale, et al. observed a significant gap between guideline recommendations and hypertension care in Nigeria and this situation is further worsened by the general unawareness of current management guidelines among primary care physicians [17].

In addition, a two-way referral system across the various levels of care is lacking in Nigeria health care system resulting in poor follow-up of hypertensive patients to reduce the burden of hypertension-related complications [26].

One key patient-related factor that determines control of hypertension is adherence to recommended therapy. Most studies on compliance with hypertension treatment in Nigeria reported figures ranging from 29\% to 50\% [27-29]. Adherence/Non-adherence to recommended treatment is dependent on individual factors such as pre-existing beliefs and perception about the illness and available treatment modalities. Patients are often worried about the lifelong nature of essential hypertension and the requirement for prolonged therapy and life style modifications and consequently resort to endless search for 'cures' in alternative medicines, food supplements and local remedies. Adherence to hypertension treatment is also significantly influenced by socio-cultural and economic factors such as adverse traditional and cultural practices, illiteracy and poverty $[27,29]$.

\section{Conclusion}

In conclusion, effective policy strategies for appropriate intervention to control hypertension across all health care levels in Nigeria should take into cognizance the patients' socioeconomic circumstances, perceptions and concerns about their illness. These factors should be explored and intervention measures tailored to improve outcome. International migration of doctors and other skilled health workforce to developed countries can be stemmed by improving the work environment and conditions of service of the health workers. A continuing medical education of general medical practitioners in evidence-based hypertension care, as expounded in hypertension guidelines is imperative in bridging the gap between the current practice and the standard recommendations in hypertension care.

\section{References}

1. Lozano R, Naghavi M, Lim SS, et al. Global and regional mortality from 235 causes of death for 20 age groups in 1990 and 2010: A systematic analysis for the Global Burden of Disease Study 2010. Lancet. 2012; 380: 2095-2128.

PubMed: https://pubmed.ncbi.nlm.nih.gov/23245604/

2. Opie LK,Seedat YK.Hypertension in sub-Saharan African populations. Circulation. 2005; 112: 3562-3568.

PubMed: https://pubmed.ncbi.nlm.nih.gov/16330697/

3. Muna WF. Cardiovascular disorders in Africa. World Health Statistics Quarterly. 1993; 46: 125-133.

PubMed: https://pubmed.ncbi.nlm.nih.gov/8303907

4. Wang $\mathrm{H}$, Dwyer-Lindgren L, Lofgren $\mathrm{KT}$, et al. Age-specific and sexspecific mortality in 187 countries, 1970-2010: A systematic analysis for the Global Burden of Disease Study 2010. Lancet. 2012; 380: 2071-2094. https://www.thelancet.com/journals/lancet/article/PIIS0140-6736-(12)61719-X/fulltext

5. World Health Organization (WHO). Non-communicable diseases country profiles. 2011. WHO Global Report. Geneva, Switzerland, 2011. https://www.who.int/nmh/publications/ncd_profiles2011/en/

6. Oguanobi NI, Onwubere BJC, Ike SO, Anisiuba BC, Ike VO, Ejim EC, Aneke EO. Pattern of Cardiovascular Disease Admissions in the University of Nigeria Teaching Hospital Enugu, Nigeria. Nigerian $\mathrm{J}$ Cardiol. 2008; 5: 53-66. https://www.nigjcardiol.org/text.asp?2013/10/2/77/127005

7. Odili AN, Chori BS, Danladi B, Nwakile PC, et al. Prevalence, Awareness, Treatment and Control of Hypertension in Nigeria: Data from a Nationwide Survey 2017. Global Heart. 2020; 15: 47: 1-13. https://globalheartjournal.com/article/10.5334/gh.848/

8. Oparil S, Zaman MA, Calhoun DA. Pathogenesis of hypertension. Ann Inter Med. 2003; 139: 761-776.

PubMed: https://pubmed.ncbi.nlm.nih.gov/14597461/

9. Strazzullo P, Galletti F, Barba G. Altered renal handling of sodium in human hypertension: short review of the evidence. Hypertension. 2003; 41: 1000-1005. https://www.ahajournals.org/doi/10.1161/01. hyp.0000066844.63035.3a

10. MarkAL.Thesympatheticnervoussysteminhypertension:apotentiallongterm regulator of arterial pressure. J Hypertens. 1996; 14: S159-S165. PubMed: https://pubmed.ncbi.nlm.nih.gov/9120673/

11. Levy D, Larson MG, Vasan RS, Kannel WB, Ho KK. The progression from hypertension to congestive heart failure. JAMA 1996; 275: 1557-1562. PubMed: https://pubmed.ncbi.nlm.nih.gov/8622246/

12. Kannel WB, Levy D, Cupples LA. Left ventricular hypertrophy and risk of cardiac failure: insights from the Framingham Study. J Cardiovasc Pharmacol. 1987; 10: S135-S140.

PubMed: https://pubmed.ncbi.nlm.nih.gov/2485019/

13. Ogah OS, Okpechi I, Chukwuonye II, Akinyemi JO, Onwubere BJC, Falase $\mathrm{AO}$, et al. Blood pressure, prevalence of hypertension and hypertension-related complications in Nigerian Africans: A review. World J Cardiol. 2012; 4: 327-340.

PubMed: https://pubmed.ncbi.nlm.nih.gov/23272273/ 
14. Ataklte F, Erqou S, Kaptoge S, Taye B, Echouffo-Tcheugui JB, et al. Burden of undiagnosed hypertension in sub-Saharan Africa - A systematic review and meta-analysis. Hypertension 2015; 65: 291-298. https://www.ahajournals.org/doi/full/10.1161/HYPERTENSIONAHA. 114.04394

15. Salako BL, Ogah OS, Adebiyi AA, Adedapo KS, Bekibele CO, et al. Unexpectedlyhigh prevalence oftarget-organdamageinnewlydiagnosed Nigerians with hypertension. Cardiovasc J Afr. 2007; 18: 77-83. PubMed: https://pubmed.ncbi.nlm.nih.gov/17497043/

16. Ajuluchukwu JNA, Jarikre AE, Inem VA. A survey of general medica practitioners' knowledge of hypertension care: assessment of practice and choicesinfluencing management. JMedandMed Sci. 1999;1:84-89. PubMed: https://www.ncbi.nlm.nih.gov/pmc/articles/PMC5488053/

17. Ale OK, Braimoh RW. Awareness of hypertension guidelines and the diagnosis and evaluation of hypertension by primary care physicians in Nigeria. Cardiovasc J Afr. 2017; 28: 72-76.

PubMed: https://www.ncbi.nlm.nih.gov/pmc/articles/PMC5488053/

18. Lemogoum D, Seedat YK, Mabadeje AFB, Mendis S, Bovet $P$, et al on behalf of the IFHA. Recommendations for prevention diagnosis and management of hypertension and cardiovascular risk factors in sub-Saharan Africa. J Hypertens. 2003; 21: 1993-2000. https:// www.academia.edu/14235162/Recommendations_for_prevention diagnosis_and_management_of_hypertension_and_cardiovascular_ risk_factors_in_sub_Saharan_Africa

19. Frijling BD, Spies TH, Lobo CM, Hulscher M, van Drenth BB, et al Blood pressure control in treated hypertensive patients: clinical performance of general practitioners. Br J Gen Pract. 2001; 51: 9-14. PubMed: https://www.ncbi.nlm.nih.gov/pmc/articles/PMC1313918/

20. World Population Prospects 2019. United Nations, Dept of Economic and Social Affairs. 2019. https://www.un.org/development/desa/ publications/world-population-prospects-2019-highlights.html

21. Ihua B, Nsofor I. Emigration of Nigerian Medical Doctors: Survey
Report. NOIPOLLS, Nigeria Healthwatch, 2017; 1-48. https://noi-polls. com/2018/wp-content/uploads/2019/06/Emigration-of-Doctors-PressRelease-July-2018-Survey-Report.pdf

22. World Health Organization. Nigeria. In: Global Health Workforce Alliance: Annual Report 2014. Geneva: World Health Organization; 2016. https://www.who.int/workforcealliance/knowledge/resources/ghwa_ annual_report2014.pdf

23. World Health Organisation (WHO). Density of doctors, nurses and midwives in the 49 priority countries. 2010. https://www.who.int/hrh/fig_density.pdf

24. World Health Organization. Health systems. In: World Health Statistics 2014.Geneva: World Health Organization. 2014; 128-140. https:// www.who.int/news/item/15-05-2014-world-health-statistics-2014

25. Ike SO. The health workforce crisis: the brain drain scourge. Niger J Med. 2007; 16: 204-211.

PubMed: https://pubmed.ncbi.nlm.nih.gov/17937154/

26. Abdulraheem IS, Olapipo AR, Amodu MO. Primary health care services in Nigeria: Critical issues and strategies for enhancing the use by the rural communities. J. Pub. Health Epidem. 2012; 4: 5-13. https:// academicjournals.org/journal/JPHE/article-full-text-pdf/F333DB74249

27. Kabir M, lliyasu Z, Abubakar IS, Jibril M. Compliance to medication among hypertensive patients in Murtala Mohammed Specialist Hospital, Kano, Nigeria. J Community Med Primary Health Care. 2004; 16: 16-20. https://www.ajol.info/index.php/jcmphc/article/view/32401

28. Olubodun JO, Falase AO, Cole TO. Drug compliance in hypertensive Nigerians with and without heart failure. Int J Cardiol. 1990; 27: 229-234. PubMed: https://pubmed.ncbi.nlm.nih.gov/2365511/

29. Isezuo AS, Opera TC. Hypertension awareness among Nigerians in a Nigerian tertiary health institution. Sahel Med J. 2000; 3: 93-96. https://www.smjonline.org/article.asp?issn=1118-8561;year=2000; vol ume $=3 ;$ issue $=2 ;$ spage $=93$; epage $=97$; aulast $=$ Isezuo $;$ type $=0$ 